\title{
Educação não formal: atividades experimentais em uma cooperativa de catadores
}

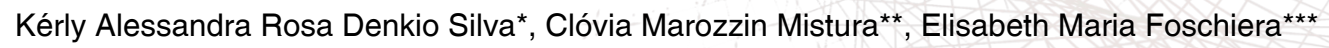

\section{Resumo}

Integrando ações do Projeto de Extensão Aulão na Cooperativa Amigos do Meio Ambiente (Coama), da Universidade de Passo Fundo (UPF), ocorreu, no segundo semestre de 2018, a realização de atividades experimentais não formais com sequências didáticas de conteúdos de Ciências e Química, desenvolvidos por uma acadêmica do curso de Química Licenciatura da UPF, destinadas aos trabalhadores da Coama. O objetivo do trabalho realizado foi possibilitar aos cooperados o acesso a alguns conceitos científicos da área Ciências Naturais, que poderão dar as explicações sobre alguns fenômenos do cotidiano desses sujeitos, bem como auxiliar para que eles consigam atingir o objetivo de certificação dos ensinos fundamental e médio, por intermédio das provas do supletivo, ofertadas pelo Núcleo de Educação de Jovens e Adultos.

Palavras-chave: Atividades experimentais. Certificação. Educação não formal. Sequências didáticas.

Acadêmica do Curso de Química Licenciatura do Instituto de Ciências Exatas e Geociências da Universidade de Passo Fundo. E-mail: 160666@upf.br

* Professora do Curso de Química Licenciatura do Instituto de Ciências Exatas e Geociências da Universidade de Passo Fundo. E-mail: clovia@upf.br

*** Professora do Curso de Pedagogia da Faculdade de Educação da Universidade de Passo Fundo. E-mail: bethfosch@upf.br

Recebido em: 27/04/2019 - Aceito em: 29/04/2019.

https://doi.org/10.5335/rbecm.v2i1.9735 


\section{Introdução}

Nas últimas décadas, têm ocorrido, no país, esforços para integrar pessoas menos favorecidas, que não tiveram oportunidade de estudar no tempo instituído, ao sistema educacional. No início dos anos 1960, apenas $45 \%$ da população frequentava a escola formal; em 1980, o percentual elevou-se para $80 \%$ e, em 1990, atingiu 86,9\% (BRASIL, 1993). Porém, ainda no século XXI, há uma porcentagem significativa de pessoas que não conseguiram frequentar a escola. Segundo o Instituto Brasileiro de Geografia e Estatística (2017), são 24,8 milhões de pessoas que não tiveram oportunidade de iniciar os estudos ou, por motivos diversos, saíram da escola, principalmente para trabalhar, sendo que 11,8 milhões de analfabetos estão excluídos do letramento no Brasil.

Entretanto, o mercado de trabalho se torna cada vez mais exigente, solicitando um mínimo de escolarização, ou seja, a conclusão dos ensinos fundamental e médio. Além da importância do conhecimento científico, devem ser compreendidos os valores e os direitos como cidadãos que devem ser desenvolvidos na educação básica, para que obtenham mais oportunidades e acesso aos seus direitos como trabalhadores e cidadãos. A Constituição cidadã brasileira (BRASIL, 1988 apud SANTOS; SCHNETZLER, 2015, p. 45), em seu artigo 205, define que: "A educação, direito de todos e dever do Estado e da família, será promovida e incentivada com a colaboração da sociedade, visando ao pleno desenvolvimento da pessoa, seu preparo para o exercício da cidadania e qualificação para o trabalho".

Tendo em vista essas reflexões, o projeto procurou auxiliar os associados da Cooperativa Amigos do Meio Ambiente (Coama) para obterem os certificados dos ensinos fundamental e médio, por intermédio das provas ofertadas no Núcleo Estadual de Educação de Jovens e Adultos (Neeja) (Centro, Passo Fundo, RS). Para que esses trabalhadores consigam adquirir o certificado, é necessário o acesso aos conceitos exigidos nas provas. Entre as diversas áreas do conhecimento trabalhadas no Projeto Aulão na Coama, estão os componentes curriculares: Ciências Naturais (ensino fundamental) e Química (ensino médio), ambos compondo a área Ciências da Natureza.

A Coama integra o Projeto Transformação, entidade que proporciona assessoramento e acompanhamento continuado a associações e cooperativas de reciclagem do município de Passo Fundo, com o objetivo de contribuir para geração de trabalho 
e renda para as famílias envolvidas, por meio de obtenção e venda de materiais recicláveis.

A concepção metodológica do trabalho realizado busca autonomia e cidadania dos sujeitos e fundamenta-se teórica e metodologicamente, também, nas Diretrizes Curriculares para a Educação de Jovens e Adultos e nas propostas descritas nos documentos dos Objetivos de Desenvolvimento Sustentável (ODS), da Agenda 2030.

AAgenda 2030 é um plano de ação para as pessoas, para o planeta e para a prosperidade. Ela também busca fortalecer a paz universal com mais liberdade. Reconhecemos que a erradicação da pobreza em todas as suas formas e dimensões, incluindo a pobreza extrema, é o maior desafio global e um requisito indispensável para o desenvolvimento sustentável (NAÇÕES UNIDAS NO BRASIL, 2015, não paginado).

As aulas, que versam sobre conhecimentos fundamentais, foram planejadas na disciplina Metodologia do Ensino de Ciências e Química do curso de licenciatura em Química da Universidade de Passo Fundo (UPF). Os encontros tiveram um espaço exclusivo na sede da associação, o Galpão da Coama, para exercer as atividades com os trabalhadores. Os encontros não se constituíram em aulas formais, mas em encontros de discussão e construção de conhecimento a partir da realidade do espaço. A participação foi voluntária, tendo como objetivo que os envolvidos compreendessem, a partir dos conceitos abordados, conteúdos de Ciências e Química, escolhidos a partir de sua vivência e que auxiliassem para o entendimento de alguns fenômenos naturais, melhorando, consequentemente, o desempenho na prova de certificação.

\section{Educação de jovens e adultos em um ambiente não formal}

“A educação não-formal está resgatando as razões e tentativas de resistência que a classe popular vem demonstrando frente às práticas de manipulação e submissão da classe dominante sobre ela" (ORTH, 2000, p. 140). Tendo em vista a necessidade de informação sobre os direitos e os deveres do cidadão, a população, cada vez mais, vem procurando participar das decisões da sociedade, e, para este empoderamento, ela deve ter acesso à escolarização.

Nesse sentido, a educação precisa aliar o conhecimento e a prática sobre manifestações da cultura popular, tendo o compromisso com a educação pública. "Isso se deve ao fato de que ao buscarmos a universalização da educação pública, que a maioria não tem acesso, e que a maioria se encontra nas camadas populares, em 
que a cultura popular se insere, surge a necessidade da orientação educacional" (ORTH, 2000, p. 146). Esta orientação promove a importância de a classe menos favorecida ter acesso à educação, da valorização dos direitos e da igualdade em todos os âmbitos.

Nessa perspectiva, homens e mulheres que têm como fonte de trabalho e renda a reciclagem mobilizam-se e lutam pela cidadania, emancipação e liberdade, visando à conquista do "ser mais", dos direitos humanos, e que a educação possa ser mediadora na construção de uma sociedade mais sustentável e humana (FORTUNA; FOSCHIERA, 2015, p. 94).

Entretanto, para uma parcela significativa da população, por motivos de opção pelo trabalho ao invés do estudo, tornaram-se difíceis o acesso à educação e a compreensão sobre os seus direitos e deveres como cidadão. A modalidade de Educação de Jovens e Adultos (EJA) busca contemplar essa população.

A EJA é uma modalidade de ensino específica para pessoas que não tiveram oportunidade de estudar no tempo certo, exigindo uso de metodologias diferenciadas, conteúdos diversificados, de modo a contribuir para que esses sujeitos possam pensar, discutir e solucionar os problemas relacionados ao seu cotidiano. Ela apresenta, na sua trajetória histórica, mais tensões sociais do que a educação básica brasileira, uma vez que envolve jovens trabalhadores pobres, negros, que vivem à margem das políticas públicas. Isso possibilita perceber que por detrás da EJA existe uma dura realidade de sujeitos excluídos, que pouco ou nunca estiveram em um ambiente escolar, ou tiveram que abandoná-lo precocemente (ARROYO, 2005, p. 23).

Segundo o Ministério da Educação e Cultura (BRASIL, 1993, p. 74), “[...] para que a educação básica se torne equitativa, é mister oferecer a todas as crianças, jovens e adultos a oportunidade de alcançar e manter um padrão mínimo de qualidade de aprendizagem". Compreendendo-se a necessidade de diminuir a desigualdade de aprendizagem, o projeto apresentado no presente trabalho procurou auxiliar os trabalhadores da Coama, os quais apresentavam dificuldades em procurar conhecimento, oferecendo oficinas e momentos não formais, envolvendo conteúdos das diversas áreas do conhecimento, para proporcionar a eles acesso à informação, auxiliando no desenvolvimento intelectual tanto para a vida pessoal quanto para a certificação da educação básica. Para tanto, os encontros são realizados no próprio ambiente de trabalho (Galpão da Coama), em horários convenientes para o grupo, assim, o deslocamento não se torna um empecilho no trabalho de triagem dos re- 
síduos realizado por eles, ocasionando uma educação não formal, a qual apresenta benefícios, pois os participantes manifestam a satisfação de se sentirem importantes e envolvidos nesse processo.

Nesse sentido:

Os espaços de educação não-formal deverão ser desenvolvidos seguindo alguns princípios; apresentar caráter voluntário, proporcionar elementos para a socialização e a solidariedade, visar o desenvolvimento social, evitar formalidades e hierarquias, favorecer a participação coletiva, proporcionar a investigação e, sobretudo, proporcionar a participação dos membros do grupo de forma descentralizada. A partir destas primeiras caracterizações, fica claro que não há como pensar a educação não-formal desconsiderando a comunidade, pois é difícil o envolvimento voluntário das pessoas com algo com o qual não se identificam (SIMSON, 2001, p. 11 apud GADOTTI, 2009, p. 3).

Os encontros descritos neste artigo são exclusivos sobre os conceitos de Ciências e Química, porém, é importante ressaltar que, em outros momentos, o grupo tem acesso a conteúdos de outros componentes e de outras áreas. Os encontros foram organizados pela professora e acadêmica de Química Licenciatura e tiveram como objetivo a compreensão dos conceitos de Ciências/Química, auxiliando no entendimento dos fenômenos naturais do cotidiano dessas famílias, na melhora da qualidade de vida e, consequentemente, no bom desempenho nas provas de certificação.

\section{Experimentação}

Os encontros desenvolvidos tiveram caráter dialógico, visual e experimental, pois a maioria dos envolvidos está em processo de alfabetização. Considerando o pleno desenvolvimento, foram preparados e utilizados materiais que são facilmente encontrados no cotidiano do grupo, para discutir os conceitos específicos e buscar uma melhor interação com o mundo material conhecido por eles. O cotidiano das pessoas e seu contexto podem ser concebidos como a linguagem e o discurso que dominam. "Uma sequência efetivamente contextualizada precisa partir do que os sujeitos conseguem falar e se expressar sobre o mundo" (MORAES, 2008, p. 18).

Para Darroz, Rosa e Rosa (2015, p. 87): “Os conhecimentos prévios, denominados por Ausubel conceitos subsunçores, são compreendidos como um conceito capaz de servir de ancoradouro a uma nova informação". Quando os trabalhadores trazem seus conhecimentos prévios, torna-se muito mais eficaz seu desempenho no processo, pois os envolvidos conseguem fazer relações entre suas experiências de vida e os 
conceitos científicos. Nessa perspectiva, para que os participantes puderam trazer experiências de vida, a partir do que conseguiam relacionar com que estavam visualizando, tornando-se parte do processo de aprendizagem.

Os envolvidos neste processo são adultos que já tiveram contato com diversos conhecimentos químicos, físicos e biológicos, entretanto, não houve contextualização científica. "Poderíamos argumentar que não é necessário ter acesso a um conhecimento científico da realidade para interagir com ela. No entanto, o que tratamos é da qualidade da interação" (FUMAGALLI, 1998, p. 17). Dessa forma, compreendemos que, além de interagir, deve-se entender cientificamente os fenômenos que ocorrem no mundo material, podendo melhorar a ação e remediar as interações entre conceitos e realidade. Chassot (2000, p. 38) complementa, “[...] considerando o ensino de ciências a partir da ideia de alfabetização científica, 'como o conjunto de conhecimentos que facilitariam aos homens e mulheres fazer uma leitura do mundo onde vivem"'.

Assim, justifica-se a importância de trazer perspectivas do cotidiano, pois, conhecendo de forma científica como o mundo material se comporta, é possível compreender e evitar incidentes do dia a dia do complexo trabalho de triar os resíduos alheios e interagir com este meio de forma prática e eficiente. "Estes cidadãos poderão perceber sua importância no ciclo socioambiental na sociedade e agir também de forma responsável pelos cuidados do meio ambiente, valorizando-se como trabalhadores importantes na sociedade de consumo atual" (ABATTI; MISTURA, 2009, p. 113).

Para se obter um ensino significativo, torna-se fundamental utilizar atividades experimentais que auxiliem na construção dos conhecimentos científicos. Acerca dos benefícios, Lauxen, Vaniel e Linck (2015, p. 102) afirmam que:

[...] as contribuições das atividades experimentais são plurais e permitem especialmente a compreensão de fenômenos, no desenvolvimento de habilidades de expressão escrita e oral, no uso da linguagem química, na elaboração de conceitos, na elaboração de hipóteses, etc.

Durante o desenvolvimento das atividades experimentais, os trabalhadores foram frequentemente questionados, para que apresentassem hipóteses e soluções sobre a atividade que estava sendo desenvolvida.

Segundo Azevedo (2004, p. 21), o sujeito “[...] deve refletir, discutir, relatar o que dará ao seu trabalho as características de uma investigação científica”. Com essa perspectiva, foram propostas atividades experimentais com objetos e discussões da realidade local, para que fosse possível uma efetiva construção do conhecimento científico. 


\section{Metodologia}

Os encontros relatados neste artigo foram planejados e desenvolvidos por uma acadêmica do curso de Química Licenciatura, com a orientação da professora formadora. Em conjunto, ambas organizaram os momentos e o material pedagógico, bem como o roteiro dos encontros, planejando o momento especialmente para este público. Os encontros acontecem uma vez por semana, na cooperativa em que os envolvidos trabalham, visando uma educação não formal. Neste trabalho, são sistematizados os resultados de dois encontros, sendo que cada encontro teve duração aproximada de 30 minutos.

\section{Resultados e discussão}

Para a realização dos encontros, foi produzido um mapa conceitual com a ajuda dos documentos que orientam a realização dos exames do Exame Nacional para Certificação de Competências de Jovens e Adultos (ENCCEJA). O mapa é apresentado na Figura 1.

Figura 1 - Mapa conceitual da sequência didática discutida na Coama

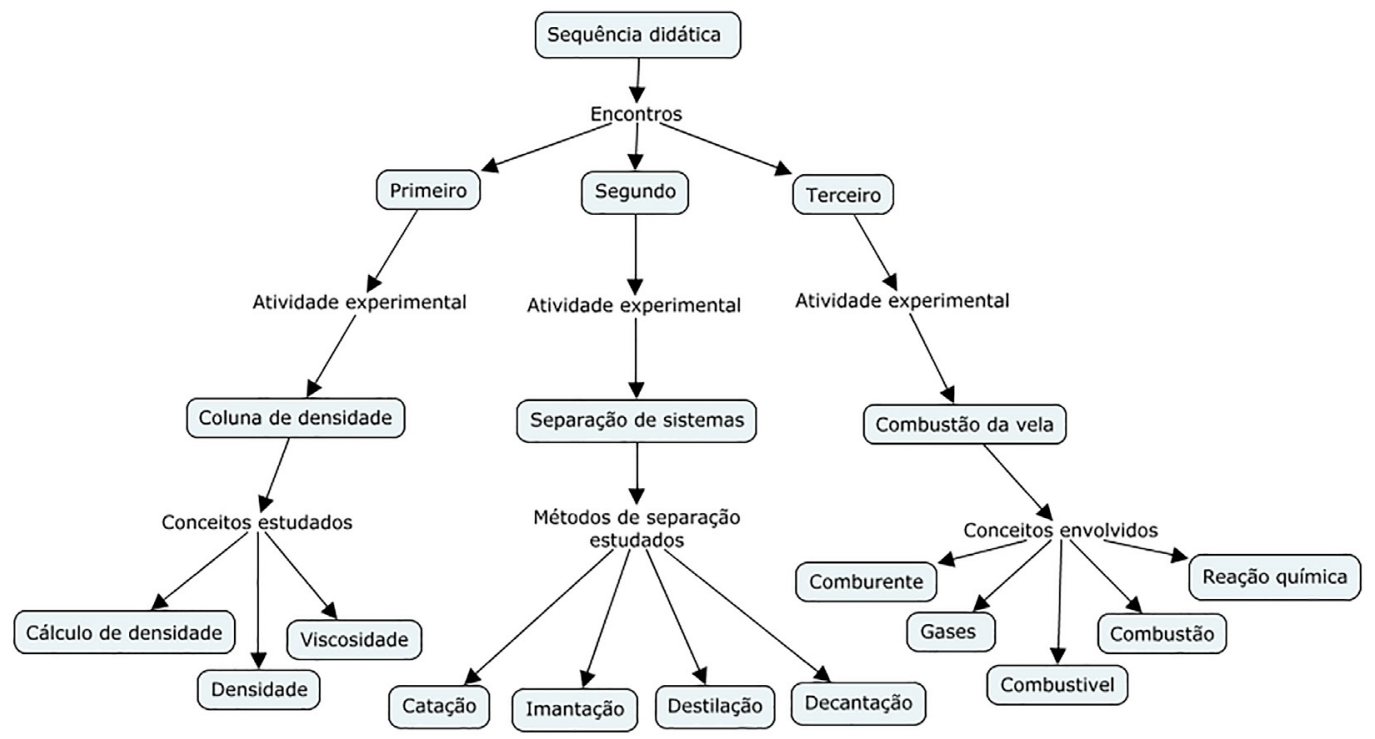

Fonte: autores. 
O primeiro encontro teve como objetivo principal compreender o conceito de densidade. Inicialmente, questionou-se sobre o sistema água e óleo, solicitou-se que os participantes relatassem em que momento já viram este sistema e como se comporta a água em contato com o óleo de cozinha, para, posteriormente, ser realizada a atividade experimental denominada "coluna de densidade", na qual são transferidos, para uma proveta de capacidade de $50 \mathrm{~mL}, 15 \mathrm{~mL}$ de óleo de cozinha, que a própria cooperativa recolhe, adicionando $15 \mathrm{~mL}$ de água, após alguns segundos, até que o sistema estabilize, com a água se depositando abaixo do óleo na coluna pela diferença de densidade; posteriormente, são adicionados, delicadamente, $15 \mathrm{~mL}$ de álcool etílico comum e, por último, um comprimido efervescente. A atividade está relatada na Figura 2, na qual se observa o local em que foram realizados os encontros e a distribuição informal do grupo, ao longo de uma mesa, interagindo com a acadêmica por meio de conversas e discussões sobre os experimentos realizados.

Figura 2 - Primeiro encontro - Coluna de densidade

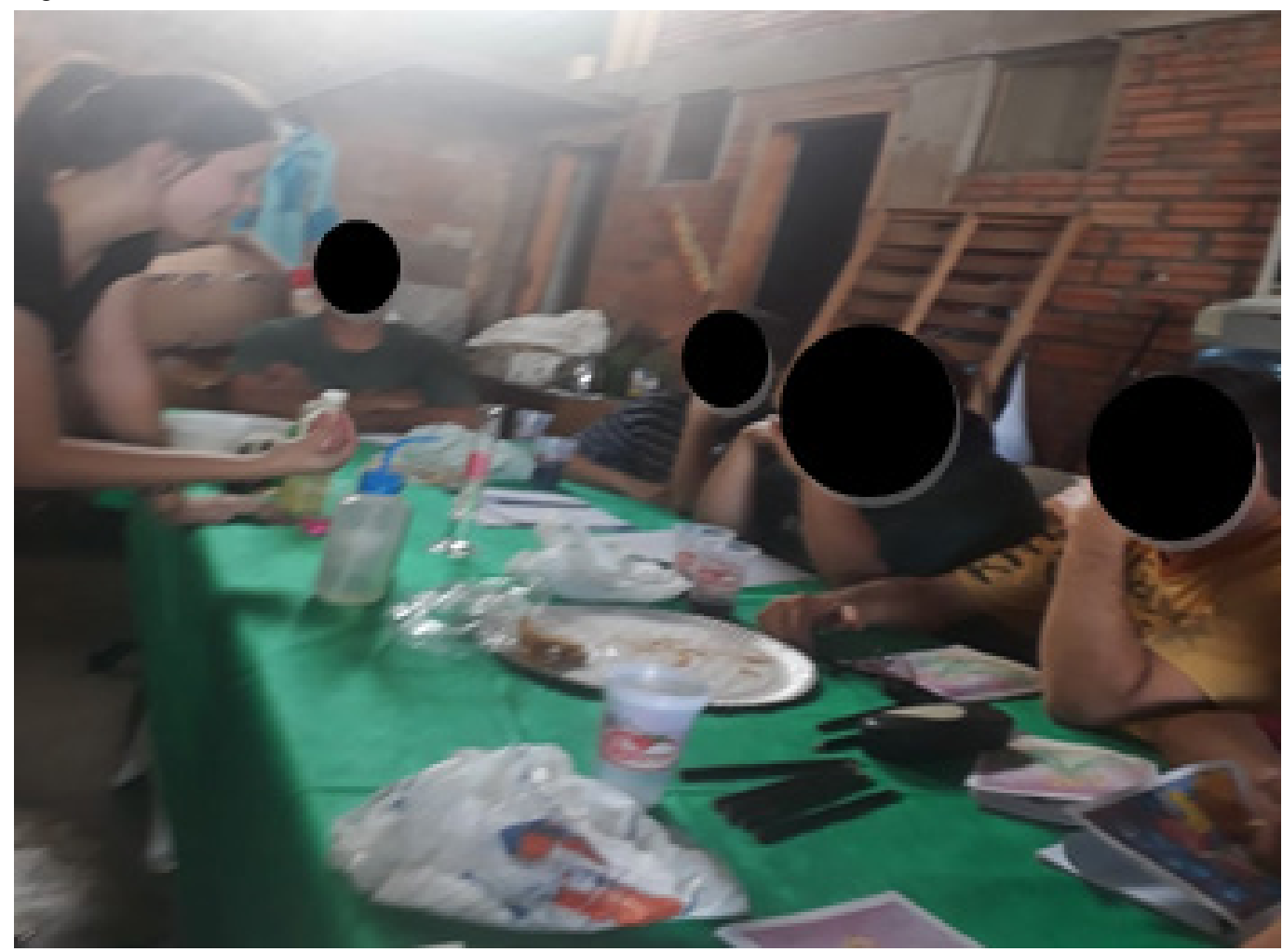

Fonte: autores. 
A cada etapa, os participantes foram questionados, para formularem hipóteses do que iria acontecer na coluna de densidade. A partir da atividade experimental, foi sistematizado o conceito de densidade, com o auxílio do material pedagógico produzido anteriormente.

Como atividade de sistematização, foi proposto que os participantes inferissem a densidade de um pedaço de granito, foi informada apenas a massa do granito e, com o auxílio da acadêmica, foram colocados $20 \mathrm{~mL}$ de água na proveta, depois foi colocado o pedaço de granito dentro da proveta; pelo aumento e pela diferença de volume, foi possível descobrir a relação do volume do pedaço de granito, a partir desta informação, foi explicada a utilização do cálculo de densidade, a partir desta atividade experimental.

O segundo encontro teve como objetivo conceituar os processos de separação de sistemas. Incialmente, foi solicitado que os participantes se organizassem em quatro grupos, e cada grupo recebeu um recipiente com um sistema simples, com materiais do seu cotidiano para efetuar a caracterização e propor a separação dos componentes:

1- arroz + feijão + pipoca;

2- farinha + limalha de ferro;

3- água + sal;

4- água + óleo de cozinha.

Para incentivar o raciocínio científico para a identificação e a posterior proposta de separação dos componentes dos sistemas apresentados, foi dado um tempo de 5 minutos para os grupos, que foram orientados a formular hipóteses de formas de separação. Após este período, cada grupo fez o relato dos métodos sugeridos para obter cada componente do sistema separadamente e explicaram o motivo da escolha de cada opção.

Para concluir a atividade, foi realizada a separação do recipiente 2 e 4 , foram conceituadas as quatro formas de separação propostas pelos grupos (catação, imantação, destilação e decantação) e as fases desses sistemas.

Os próximos encontros estão em fase de planejamento. No terceiro encontro, será discutido o conceito de combustão, a partir de uma atividade prática (combustão da vela), na qual será possível discutir os temas envolvidos nas reações para produção de energia e combustíveis, bem como os produtos que resultam dessas reações. Essas sequências foram planejadas para proporcionar a construção de diversos conceitos e explicações para fenômenos que ocorrem no cotidiano dos indivíduos. 


\section{Considerações finais}

Durante a realização das atividades, os envolvidos se mostraram muito interessados, respondendo aos questionamentos realizados pela acadêmica e, em todos os momentos, interagindo com dúvidas genuínas e práticas, fazendo relação com experiências do seu cotidiano. As sequências didáticas não formais podem ser aplicadas em diversos grupos e o resultado se dará na construção dos conceitos, ao final das atividades.

A maioria dos envolvidos relatou que nunca teve contato com livros de Ciências e Química ou com salas de aula formais, contudo, suas experiências são muito ricas e podem ser o início das discussões para a aprendizagem de uma ciência conceitual e aplicada, pois, ao longo da vivência, constroem-se os conceitos próprios de como o mundo material se comporta perante algumas circunstâncias.

Esta oportunidade está agregando muita satisfação e valor a todos os envolvidos, tanto para os trabalhadores participantes, que estão tendo acesso à informação e à compreensão dos fenômenos do cotidiano, quanto para a acadêmica, que está tendo uma oportunidade de colocar em prática algumas das metodologias estudadas no curso de licenciatura.

\section{Non-formal education: experimental activities in a recyclers cooperative}

\section{Abstract}

In the second semester of 2018, the University of Passo Fundo (UPF) was involved in the extension project in the Cooperative Friends of the Environment (CFE), where non-formal experimental activities were carried out with didactic sequences of Science and Chemistry content developed by a course academic of Chemistry Graduation of UPF, destined to the workers of CFE. The objective of the work was to provide the cooperative with access to some scientific concepts in the area of Natural Sciences, which can provide explanations about some phenomena in the daily life of these subjects, as well as help them achieve the objective of certification of Elementary School and / or Medium, through the tests of the supplementary, offered by the Nucleus of Education of Young and Adults.

Keywords: Experimental activities. Certification. Non-formal education. Didactic sequences. 
ABATTI, A. L.; MISTURA, C. M. Consumo consciente $\mathrm{x}$ sustentabilidade: o que isso tem a ver com os produtos que eu levo para casa? In: EDUCAÇÃO e ética do cuidado - os múltiplos olhares da educação socioambiental. Passo Fundo: Imed Editora, 2009. p. 112-128.

ARROYO, Miguel Gonzales. Educação de jovens e adultos: um campo de direitos e responsabilidade pública. In: SOARES, L. J. G.; GIOVANETTI, M. A.; GOMES, N. L. Diálogos na educação de jovens e adultos. Belo Horizonte: Autêntica, 2005. p. 19-50.

AZEVEDO, M. C. P. S. Ensino por investigação: problematizando as atividades em sala de aula. In: Carvalho, A. M. P. (org.). Ensino de Ciências - unindo a pesquisa e a prática. São Paulo: Thomson, 2004. p. 9-28.

BRASIL. Ministério da Educação e Cultura. Plano decenal de educação para todos. Brasília, DF: MEC, 1993.

CHASSOT, Attico. Alfabetização científica: questões e desafios para a educação. Ijuí: Editora Unijuí, 2000.

DARROZ, L. M.; ROSA, C. T. W. da; ROSA, A. B. da. Organizador prévio para aprendizagem significativa de conceitos iniciais da cinemática. In: STURM, L. (org.). Qualidade de ensino na educação básica: contribuições das ciências da natureza, da matemática e de suas tecnologias. Passo Fundo: UPF Editora, 2015. p. 86-96.

FORTUNA, V.; FOSCHIERA, E. M. O catador e a reciclagem: uma alternativa coletiva de trabalho e renda. In: SILVA, E. M. T. da; VIRGOLIN, I. W. C.; CAMARGO, M. A. S. (org.). Profissão catador: alternativas coletivas na geração de trabalho e renda. Curitiba: Editora CRV, 2015. v. 1. p. 81-96.

FUMAGALLI, L. O ensino de ciências naturais no nível fundamental da educação formal: argumentos a seu favor. In: WEISSMAAN, H. et al. Didática das ciências naturais: contribuições e reflexões. Porto Alegre: Artmed, 1998. p. 13-29.

GADOTTI, M. Educação integral no Brasil - inovações em processo. São Paulo: Instituto Paulo Freire, 2009. (Série Educação Cidadã). Disponível em: http://www.acervo.paulofreire.org:8080/ jspui/bitstream/7891/3079/1/FPF_PTPF_12_076.pdf. Acesso em: 27 jul. 2019.

INSTITUTO BRASILEIRO DE GEOGRAFIA E ESTATÍSTICA. Censo geral. 2017. Disponível em: https://www.ibge.gov.br/. Acesso em: 3 out. 2018.

LAUXEN, A. A.; VANIEL, A. P. H.; LINCK, M. R. Trabalhando com situações de estudo para a construção dos conceitos de Ciências Naturais no ensino fundamental. In: STURM, L. (org.). Qualidade do ensino na educação básica: contribuições das ciências da natureza, da matemática e de suas tecnologias. Passo Fundo: UPF Editora, 2015. p. 21-34.

MORAES, S. P. G. Avaliação do processo de ensino e aprendizagem em matemática: contribuições da teoria histórico-cultural. 2008. Tese (Doutorado em Educação) - Faculdade de Educação, Universidade de São Paulo, São Paulo, 2008. Disponível em: doi:10.11606/T.48.2008.tde-16032009145709. Acesso em: 24 jul. 2019.

NAÇÕES UNIDAS NO BRASIL. Agenda 2030. 2015. Disponível em: https://nacoesunidas.org/ pos2015/agenda2030/. Acesso em: 4 fev. 2018. 
ORTH, M. R. B. Cultura popular e orientação educacional. In: RAYS, O. A. (org.). A educação e ensino: constatações, inquietações e proposições. Passo Fundo: Fapergs, 2000. p. 139-149.

SANTOS, W. L. P.; SCHNETZLER, R. P. Educação em Química: compromisso com a cidadania. 4. ed. Ijuí: Editora Unijuí, 2015. 